\title{
Blood Levels of Carbonic Anhydrase 9 Correlate with Clear Cell Renal Cell Carcinoma Activity
}

\author{
Peter Hulick • Michael Zimmer • Vitaly Margulis • \\ Steven Skates • Maureen Hamel • Douglas M. Dahl • \\ Dror M. Michaelson • Towia Liebermann • \\ Sabina Signoretti • Walter Carney • Christopher Wood • \\ Othon Iliopoulos
}

Published online: 12 July 2008

(C) Humana Press 2008

\begin{abstract}
Introduction Biomarkers for early detection of renal cell carcinoma (RCC) may help diagnose minimal residual disease in patients at risk for RCC, can guide antiangiogenic therapy, or may help identify candidates for adjuvant treatment. In this study, we investigated whether blood levels of carbonic anhydrase 9 (CA9) correlate with RCC tumor burden and therefore disease activity.
\end{abstract}

P. Hulick • M. Zimmer • M. Hamel • D. M. Michaelson ·

O. Iliopoulos $(\triangle)$

Massachusetts General Hospital Cancer Center,

55 Fruit Street,

Boston, MA 02114, USA

e-mail: oiliopoulos@partners.org

S. Skates

Department of Biostatistics, Massachusetts General Hospital,

Boston, MA, USA

D. M. Dahl

Department of Urology, Massachusetts General Hospital,

Boston, MA, USA

T. Liebermann

Beth Israel Deaconess Medical Center,

Boston, MA, USA

S. Signoretti

Department of Pathology, Brigham and Women's Hospital,

Boston, MA, USA

W. Carney

Siemens Diagnostics Inc.,

Boston, MA, USA

V. Margulis $\cdot$ C. Wood

Department of Urology, MD Anderson Cancer Center,

Houston, TX, USA
Methods CA9 is a von Hippel-Lindau-hypoxia inducible factor target upregulated in clear cell RCC. We used an anti-CA9 antibody (M75)-based enzyme-linked immunosorbent assay test to measure CA9 levels in blood obtained before and after nephrectomy for clinically localized disease in patients with: (1) clear cell RCC, (2) papillary and chromophobe RCC or oncocytoma, or (3) benign kidney lesions, and we compared these samples to blood drawn from normal control individuals.

Results We observed a significant $(p<0.006)$ decrease in the blood levels of CA9, after nephrectomy for localized disease, in the majority of patients with clear cell RCC (57\%). In contrast, patients with nonclear cell RCC, benign disease, or those having undergone debulking nephrectomy for metastatic disease did not have a decrease in CA9 blood levels after nephrectomy. Preliminary longitudinal follow up measurements of CA9 levels in a small group of patients indicated that rising CA9 levels may correlate with disease progression.

Conclusions Plasma CA9 levels correlate with disease activity in a subset of clear cell RCC patients and should be considered in future multiplex RCC biomarker development algorithms.

Keywords Renal cell carcinoma - Circulating biomarker . VHL - Carbonic anhydrase 9 - Angiogenesis .

Hypoxia inducible factor

\section{Introduction}

The incidence of renal cell carcinoma (RCC) has steadily risen in the United States since 1970 and is currently estimated at approximately 51,000 cases per year. This 
increase has been observed across gender and race, increasing among black males and females by $3.9 \%$ and $4.3 \%$ per year, and white males and females by $2.3 \%$ and $3.1 \%$ per year, respectively [1]. The majority of sporadic clear cell carcinoma is of clear cell histology (75\%), followed by papillary type I (5\%) and type II (5\%), as well as chromophobe and oncocytoma $(15 \%)$. It is clear that distinct molecular mechanisms underlie each histologic type [2].

Organ-confined disease is treated with surgery. The 5year survival rate for patients presenting with stage I disease is $95 \%$, while the survival rate for patients with stage II and III RCC is decreased to $70-80 \%$ and $40-60 \%$, respectively [3]. It is therefore reasonable to assume that early disease detection would improve overall survival in RCC patients.

Medical treatment of clear cell RCC patients has been evolving rapidly. Understanding of the von Hippel-Lindau (VHL) signaling pathway and its deregulation during clear cell RCC development has led to the identification of rational molecular therapeutic targets. Clinical trials with small molecule inhibitors of the vascular endothelial growth factor, platelet-derived growth factor, and other receptor or nonreceptor cellular kinases, such as mammalian target of rapamycin, show promising results [4-9].

Targeted therapy has opened a new set of possibilities and questions in RCC treatment. Tumor response by classical imaging criteria fails to reflect changes in tumor vessel density, tumor viability, or correlate with disease progression or even overall survival. The availability of biomarkers that reflect disease activity may therefore help guide therapy. Biomarkers that serve as surrogate markers of tumor response will expedite a large number of clinical trials in which kinase inhibitors are used in combination in patients both pre- and postsurgery. Treatment of patients with minimal residual disease may prove, now that effective therapies are available, to be a better approach than treatment following clinical detection. Adjuvant trials may target patients with biomarker-detected minimal residual disease after nephrectomy for the primary tumor.

Many laboratories are therefore interested in the discovery and validation of specific and sensitive biomarkers of disease activity in the blood and/or urine of RCC patients. Here, we examined the expression of carbonic anhydrase 9 (CA9) as a potential circulating blood biomarker of clear cell RCC activity. The majority of clear cell renal cell cancers are deficient in VHL function and they are characterized by upregulation of hypoxia inducible transcription factors (HIF) 1a and HIF2a. CA9 is a transmembrane glycoprotein involved in regulation of extracellular and intracellular $\mathrm{pH}$. CA9 is a direct target of HIF1a and is greatly upregulated in primary and metastatic RCC lesions [10, 11]. CA9 has a restricted pattern of expression in normal tissues; it is detected in the epithelium of the stomach, gallbladder, and exocrine pancreas. Retrospective analysis of patients treated with high-dose interleukin (IL)-2 indicated that CA9 may predict response to this therapy [12-14] and gene expression levels of CA9 in primary tumor may correlate with higher risk for metastasis [14].

Because CA9 is linked to hypoxia-HIF-VHL signaling and appears to have a restricted expression pattern in adult tissue, we decided to investigate its value as a blood circulating biomarker for RCC by measuring CA9 expression in the plasma/serum of patients with clinically localized disease pre- and postnephrectomy. To the best of our knowledge, this is the first circulating biomarker reported to decrease in the blood of RCC patients after nephrectomy and/or to correlate with changes in tumor burden.

\section{Materials and Methods}

\section{Cell Lines and Culture}

The human RCC cell lines 786-O, UMRC2, UMRC3, and UMRC6 (obtained through American Type Culture Collection) lack wild-type VHL. Parental cell lines were used to derive isogenic clones stably expressing hemagglutinin (HA)-VHL30 or VHL-19 or harboring empty pRC/CMV plasmid as a control. Transfections were performed with Lipofectamine 2000 using manufacturer's instructions and clones were generated by neomycin selection. Cells were grown in Dulbecco's modified Eagle's medium (Media Tech) with $10 \%$ fetal clone (Hyclone Laboratories) plus one times penicillin-streptomycin-glutamine solution $(100 \times$; Invitrogen Life Sciences), supplemented with neomycin at the appropriate concentration for each cell line.

\section{RNA Extraction/qRT-PCR}

Normal human RNA control samples were obtained from Stratagene. The tissues included kidney, liver, brain, skin, and spleen. RNA was isolated from cells at $80-90 \%$ confluence. RNA was isolated using $6 \mathrm{~mL}$ of TRI Reagent LS (Molecular Research Center) and purified over RNeasy Mini Kit columns (Qiagen) and eluted into $30 \mu \mathrm{L}$ of diethyl pyrocarbonate-treated distilled water. RNA ( $1 \mu \mathrm{g}$ total $)$ was reverse transcribed to cDNA using Super Script III (Invitrogen) according to manufacturer's protocol.

Quantitative real-time polymerase chain reaction (qRTPCR) was performed per the manufacturer's recommendations using the SYBR Green Detection System (BioRad). Intron spanning primers for CA9 were designed (forward: 5'-GAGGATCTACCTGGAGAGGA-3'; reverse: 5'-CTGG AAGCCCAGGAGTTCCA-3'). Quantitation of B-globulin 
(forward 5'-TTT CAT CCA TCC GAC ATT GA-3'; reverse: 5'-ATC TTC AAA CCT CCA TGA TG-3') was performed and used for normalization of gene expression data. Each sample was run in triplicate. RNA sample without RT polymerase was used as a negative control. All PCR products were sequenced to confirm the identity of the amplified gene.

\section{Microarray Analysis}

RNA extraction and cDNA generation from RCC frozen tissue samples for gene expression profiling using $\mathrm{HG}$ U133A Affymetrix GeneChips has been previously described [15].

\section{Western Blot Analysis}

Cells were washed twice with ice cold phosphate buffered saline and lysed in radio-immunoprecipitation assay buffer (50 mM Tris $\mathrm{pH} 8.0,150 \mathrm{mM} \mathrm{NaCl}, 1 \% \mathrm{NP}-40,0.5 \%$ deoxycholate, $0.1 \%$ sodium dodecyl sulfate (SDS), and $0.02 \% \mathrm{NaN} 3$ ) supplemented with proteinase inhibitors $(20 \mu \mathrm{g} / \mathrm{mL}$ trypsin inhibitor, $10 \mu \mathrm{g} / \mathrm{mL}$ leupeptin, $200 \mu \mathrm{M}$ NaOrthovanadate, $5 \mu \mathrm{g} / \mathrm{mL}$ pepstatin $\mathrm{A}, 20 \mu \mathrm{g} / \mathrm{mL}$ aprotinin, $100 \mathrm{mM} \mathrm{NaF}$, and $200 \mu \mathrm{g} / \mathrm{mL}$ phenylmethylsulphonyl fluoride). Protein concentration was estimated by the Bradford method. Proteins were resolved (BioRad) by SDS-polyacrylamide gel electrophoresis and transferred onto polyvinylidene fluoride membrane (BioRad) for immunoblotting.

\section{Antibodies}

Antibodies for Western blot were used at indicated dilutions: anti-HIF-2a polyclonal (Novus NB100-122, 1:1,000), antiactin monoclonal (Abcam Ab8226, 1:1,000), anti-HA monoclonal (Abcam, 12CA5, 1:1,000), anticarbonic anhydrase 9 monoclonal (M75, gift from Novartis, 1:3,000). Secondary horseradish peroxidase-conjugated antibodies to mouse or rabbit IgG were purchased from Pierce and detected by Western Lighting Chemiluminescence Reagent Plus (Perkin Elmer, NEL105) according to the manufacturer's protocol.

\section{ELISA}

Enzyme-linked immunosorbent assay (ELISA) of human plasma or serum for carbonic anhydrase 9 was performed in triplicate using the commercially available MN/CAIX ELISA kit (Siemens Diagnostics). Solid phase sandwich ELISA was performed per manufacture's protocol which has an analytic range of 0 to $1,500 \mathrm{pg} / \mathrm{mL}$ and a sensitivity of $2.5 \mathrm{pg} / \mathrm{mL}$ per product literature.

\section{Human Sample Collection}

Plasma, serum, and urine from patients with renal cell carcinoma have been collected, under prior Institutional Review Board approved protocol, before nephrectomy for localized disease and at regular intervals following nephrectomy. Blood samples were then centrifuged at $3,500 \mathrm{rpm}$, aliquoted, and stored at $-80^{\circ} \mathrm{C}$ until processing. Tumor samples were frozen and stored after pathology evaluation to determine histological subtyping. All patients provided informed consent for tumor and blood sample collection.

\section{Results}

Loss-of-VHL function and constitutive upregulation of the transcription factor hypoxia inducible factor is the earliest known molecular event in the majority of clear cell RCC. Reconstitution of the VHL function by stable reintroduction of VHL (either the 30 or $19 \mathrm{kDa}$ isoform) or inactivation of the HIF protein leads to growth suppression of these cell lines as tumors in the xenograft assay [16-18]. These observations indicate that the fundamental signaling pathways implicated in renal carcinogenesis are intact in these cell lines. In order to identify candidate biomarkers for RCC, we compared the gene expression profile of human renal cell carcinoma cell lines that are deficient in VHL tumor suppressor protein to their isogenic counterparts that stably express VHL.

One of the messages upregulated by loss-of-VHL function, as measured by DNA microarray, was the transmembrane glycoprotein carbonic anhydrase 9. To validate the microarray data and to test whether differences at the mRNA level reflect differences in protein expression in various cell lines, we examined CA9 mRNA and protein expression in human RCC cell lines under identical culture conditions. CA9 protein expression was analyzed by Western blot (Fig. 1a) in VHL deficient cell lines 786-O, UMRC2, and UMRC6 (lanes 1, 3, and 5 of Fig. 1a) and their corresponding isogenic clones that express VHL30 or VHL19 (Fig. 1a, lanes 2, 4, and 6). CA9 mRNA expression was examined by qRT-PCR (Fig. 1b). The high expression of the CA9 message in UMRC2 cells (Fig. 1b, lane 3) corresponds to a robust signal for CA9 in Western blot analysis (Fig. 1a, lane 3), while the much weaker mRNA expression in lines 786-O and UMRC6 (Fig. 1b, lanes 1 and 5) resulted in no detectable protein (Fig. 1a, lanes 1 and 5). These experiments encouraged us to interrogate the expression of CA9 in matched tumor-normal tissue samples as well as adult normal tissues.

To this end, we compared the expression of CA9 by oligonucleotide microarray in ten specimens of clear cell 
a
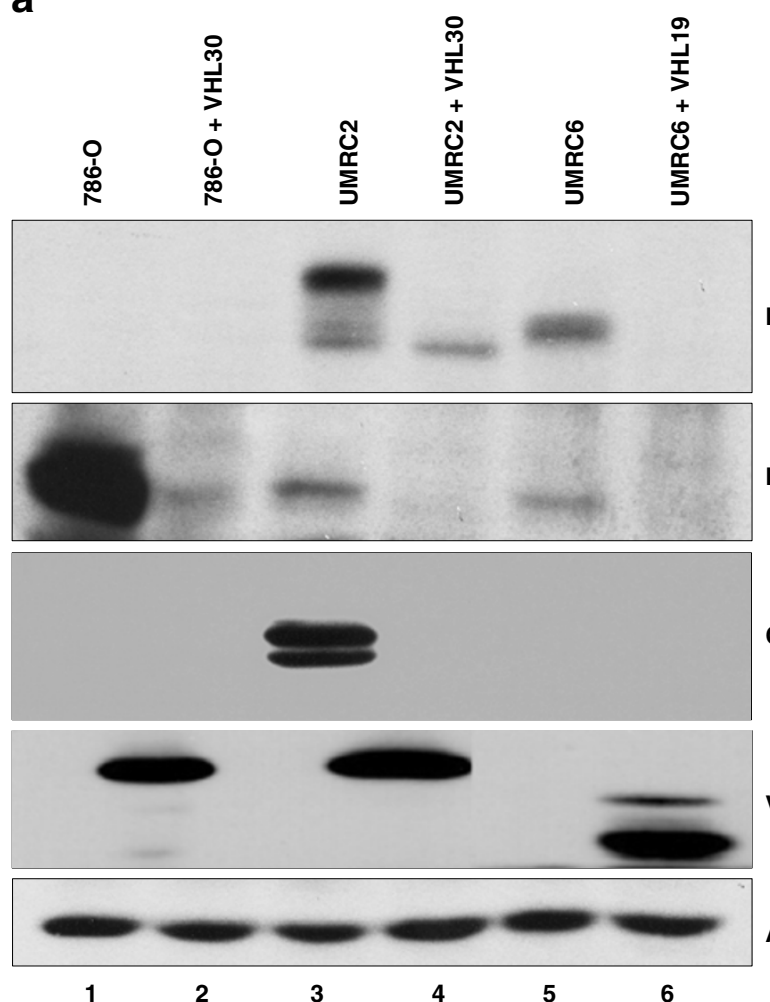

Actin

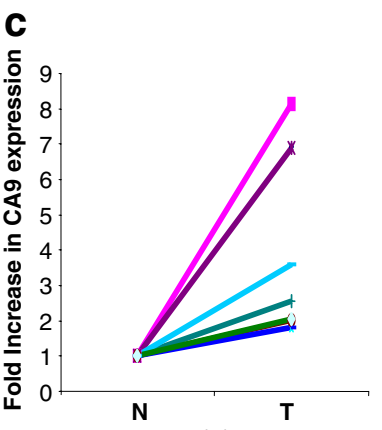

(A)

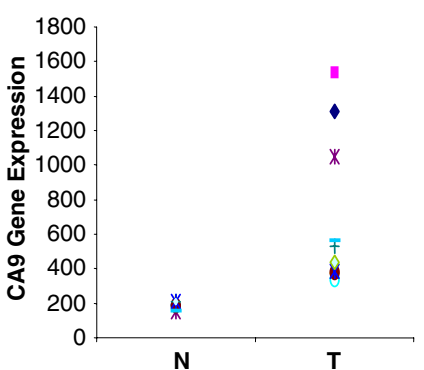

(B)

Fig. 1 Expression of carbonic anhydrase 9 (CA9) in human renal cell carcinoma cell lines and tumors. a Cell lysates of clones derived from human renal cell carcinoma cell lines 786-O, UMRC2, and UMRC6 stably transfected with vector control plasmid (lanes 1, 3, and 5) or plasmids expressing VHL30 (lanes $2 a$ and 4) or VHL19 (lane 6) were immunoblotted for HIF1a, HIF2a, VHL, and CA9 as indicated. Actin

RCC tumor $(\mathrm{T})$ to matched normal renal parenchyma $(\mathrm{N})$ obtained from the same individuals. CA9 was upregulated in all RCC specimens compared to normal matched tissue (Fig. 1c, A). Moreover, there was essentially no overlap between absolute values of mRNA signal detected in RCC tumors $(\mathrm{T})$ compared to normal matched parenchyma $(\mathrm{N}$; Fig. 1c, B).

Changes in circulating levels of a biomarker attributed to the presence of RCC may be potentially masked because of its pleiotropic expression in other tissues. Organ-restricted expression of a candidate biomarker may allow for easier

b

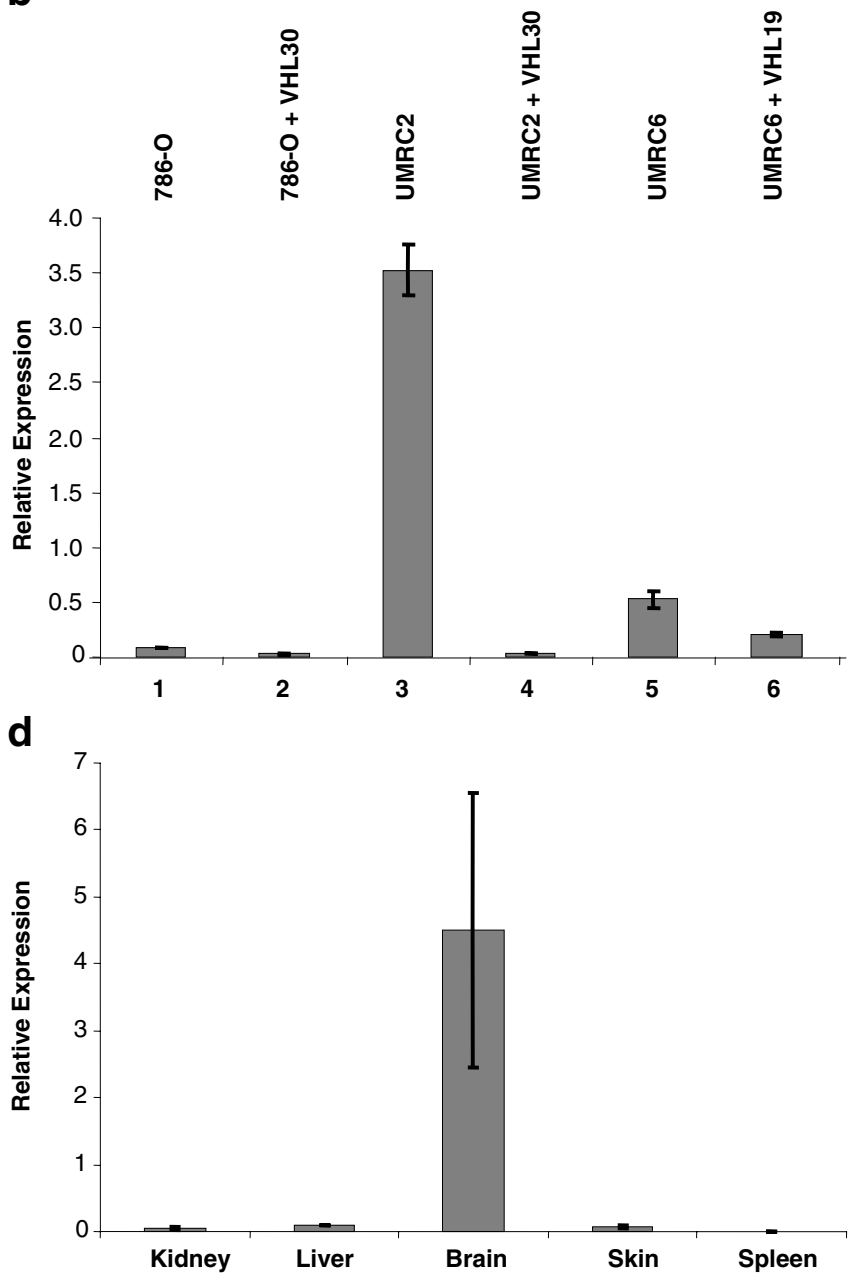

was used as loading control. b qRT-PCR of CA9 message from same cell lines. c, $A$ Fold increase of CA9 in clear cell human RCC tumor $(T)$ compared to normal $(N)$ matched kidney tissue. c, $B$ Absolute values of expression of CA9 in RCC tumor $(T)$ compared to normal $(N)$ matched kidney tissue. d Relative tissue expression of CA9 in adult human tissues

Fig. 2 Changes in blood levels of CA9 in patients having undergone curative nephrectomy for localized clear cell RCC. a MGH patients: patient sex, disease stage, tumor volume, and plasma levels of CA9 before $(P R E)$ or after (POST) nephrectomy are listed. b Correlation between tumor volume and preoperative levels of CA9 (expressed in $\log$ scale) in the MGH patient group. c MDACC patients: patient sex, disease stage, tumor volume, and serum levels of CA9 before (PRE) or after (POST) nephrectomy. d Correlation between tumor volume and preoperative levels of CA9 (expressed in log scale) in the serum of MDACC patient group. e Blood levels of CA9 before and after nephrectomy for localized RCC in all patients from the two institutions (MGH and MDACC) 
(A)

\begin{tabular}{|c|c|r|r|r|}
\hline Pt ID & SEX & PRE & POST & Tumor volume \\
\hline $\mathbf{8 7}$ & $\mathrm{M}$ & 348.12 & 277.23 & 25.625 \\
\hline $\mathbf{8 3}$ & $\mathrm{F}$ & 119.81 & 30.35 & 61.38 \\
\hline $\mathbf{9 3}$ & $\mathrm{M}$ & 155.22 & 197.62 & 33.75 \\
\hline $\mathbf{1 0 3}$ & $\mathrm{F}$ & 315.10 & 266.71 & 150 \\
\hline $\mathbf{1 0 4}$ & $\mathrm{M}$ & 381.26 & 154.65 & 67.5 \\
\hline $\mathbf{2 8}$ & $\mathrm{F}$ & 61.92 & 146.20 & 86.625 \\
\hline $\mathbf{4 6}$ & $\mathrm{M}$ & 400.79 & 488.14 & 142.5 \\
\hline $\mathbf{5 8}$ & $\mathrm{M}$ & 777.79 & 366.72 & 263.9 \\
\hline $\mathbf{6 4}$ & $\mathrm{F}$ & 137.33 & 124.63 & 34.848 \\
\hline $\mathbf{1 3 7}$ & $\mathrm{F}$ & 319.24 & 259.14 & 44 \\
\hline $\mathbf{1 4 6}$ & $\mathrm{M}$ & 201.90 & 208.27 & 36 \\
\hline $\mathbf{1 4 7}$ & $\mathrm{M}$ & 51.32 & 52.60 & 24 \\
\hline
\end{tabular}

(B)

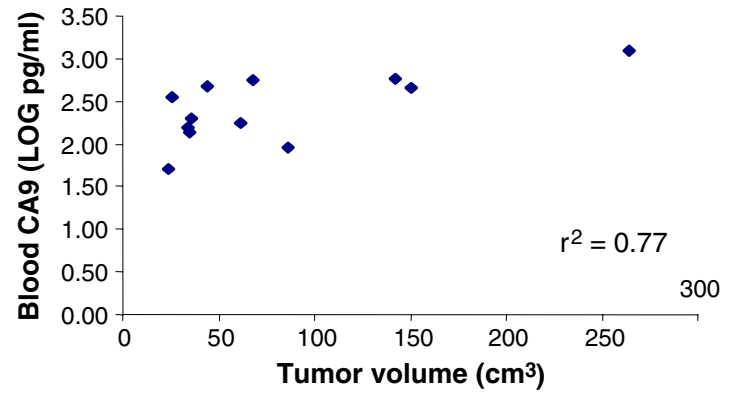

(C)

\begin{tabular}{|l|l|l|l|l|}
\hline Pt ID & SEX & PRE & POST & Tumor Volume \\
\hline
\end{tabular}

\begin{tabular}{|c|c|c|c|c|}
\hline Pt ID & SEX & PRE & POST & Tumor Volume \\
\hline 1 & Male & 226.83 & 125.15 & 665.55 \\
\hline 2 & Female & 97.55 & 149.21 & 43.75 \\
\hline 5 & Male & 317.95 & 343.95 & 88.15 \\
\hline 7 & Female & 162.86 & 215.67 & 1254.00 \\
\hline 9 & Female & 75.27 & 84.58 & 60.00 \\
\hline 10 & Female & 113.15 & 67.00 & 264.00 \\
\hline 13 & Female & 124.62 & 101.71 & 39.90 \\
\hline 18 & Male & 72.16 & 45.36 & 46.20 \\
\hline 19 & Female & 259.36 & 32.52 & 144.00 \\
\hline 22 & Male & 66.48 & 23.80 & 783.00 \\
\hline 23 & Male & 2055.16 & 1465.34 & 864.00 \\
\hline 27 & Male & 61.84 & 67.00 & 234.00 \\
\hline 29 & Male & 151.83 & 133.50 & 472.50 \\
\hline 34 & Female & 90.80 & 144.49 & 186.48 \\
\hline 35 & Female & 19.20 & 6.93 & 18.00 \\
\hline 39 & Male & 19.99 & 0.10 & 30.00 \\
\hline 40 & Female & 197.35 & 0.10 & 476.00 \\
\hline 42 & Male & 506.86 & 260.04 & 688.50 \\
\hline 43 & Female & 292.11 & 427.35 & 135.00 \\
\hline 51 & Male & 455.93 & 204.23 & 1026.00 \\
\hline 53 & Male & 31.75 & 20.61 & 14.20 \\
\hline 54 & Female & 52.21 & 89.46 & 37.44 \\
\hline 60 & Female & 113.09 & 231.17 & 80.00 \\
\hline 61 & Male & 20.61 & 0.10 & 90.00 \\
\hline 65 & Female & 4.53 & 24.94 & 137.50 \\
\hline 76 & Male & 77.03 & 93.81 & 37.44 \\
\hline 78 & Male & 95.05 & 103.76 & 392.00 \\
\hline 85 & Male & 113.09 & 106.25 & 352.87 \\
\hline 88 & Male & 143.00 & 67.72 & 54.00 \\
\hline 105 & Male & 287.45 & 120.44 & 540.00 \\
\hline 106 & Male & 828.71 & 123.09 & 273.00 \\
\hline 107 & Male & 77.34 & 58.77 & 242.00 \\
\hline 109 & Male & 170.16 & 117.79 & 162.50 \\
\hline 113 & Male & 81.98 & 75.35 & 256.00 \\
\hline 114 & Male & 312.63 & 140.33 & 90.00 \\
\hline
\end{tabular}

(D)

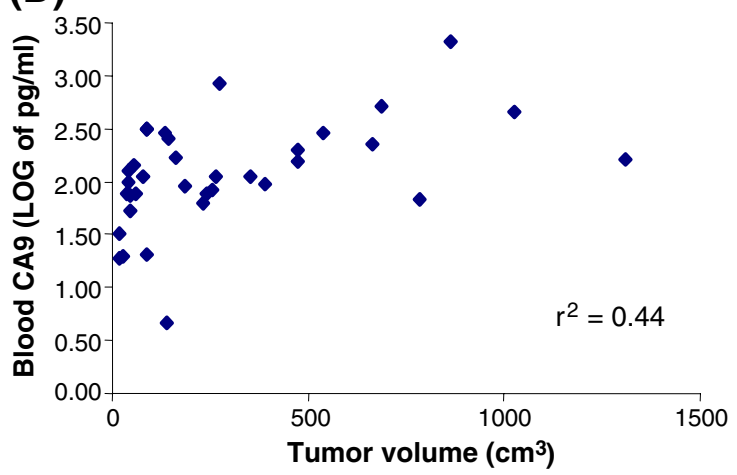

(E)

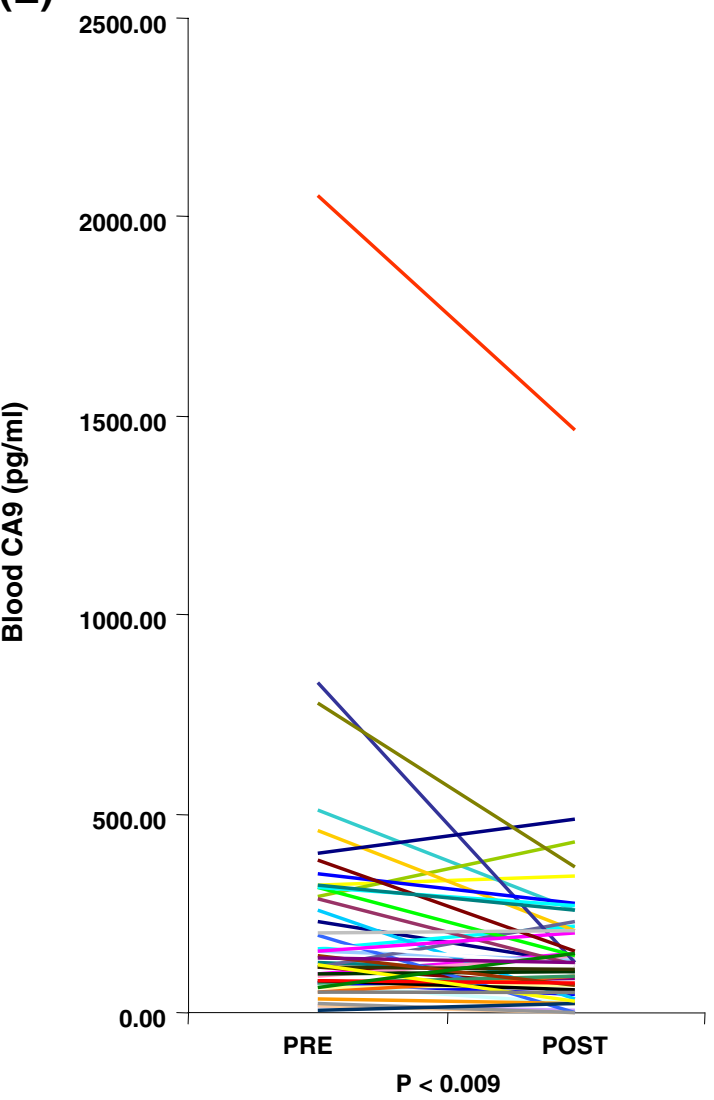


detection of incremental changes that correlate with tumor volume. We therefore examined the expression of CA9 by qRT-PCR in total RNA extracted from various adult tissues (Fig. 1d). CA9 was highly expressed in human adult brain compared to the other organs examined. Skin and liver, which are bulky organs, showed weak expression of CA9. In keeping with previous literature reports and our own microarray data, CA9 expression was very low in normal adult kidney.

To examine weather circulating CA9 levels correlated with RCC disease activity, we first measured the levels of this potential biomarker in the plasma of RCC patients with localized disease. Samples were obtained both prior to nephrectomy and between 6-8 weeks postsurgery. Figure 2a presents patient sex and tumor volume at a single institution (Massachusetts General Hospital, MGH) and circulating CA9 levels prior to (pre) and after (post) nephrectomy. Measurements were obtained with a commercially available CA9 ELISA kit (Siemens Diagnostics Inc.). The manufacturer reports and we independently confirmed, an $10 \%$ intra-assay variability. Thus, only changes greater than $10 \%$ in either direction were regarded as significant. All measurements were done in triplicate and the reported values are the mean. All tumors reported in Fig. 1 are clear cell carcinomas. Six out of 12 patients $(50 \%)$ had a decrease in postoperative values of CA9 $(50 \%)$. In three out of 12 patients $(25 \%)$, there was an increase, and the remaining three patients $(25 \%)$ had no significant difference. Although this is a small group of patients, preoperative values correlated with tumor volume (Fig. $2 \mathrm{~b} ; r^{2}=0.77$ ). To evaluate the impact of a volume "threshold" on the formation of this correlation, we remove patient 58 from the MGH group (this is the patient with the highest tumor volume). In this case, the $r^{2}$ value is reduced to 0.41 . On the other hand, if we remove patient MGH 87 (the one with the smallest tumor volume), $r^{2}$ improves to 0.83 .

To test whether these changes reflected any institutional bias and to further expand the tested population, we obtained samples of patients independently collected using a similar protocol (the exception being that serum was banked instead of plasma) at a second institution (MD Anderson Cancer Center, MDACC). We observed no significant difference between measurements of CA9 in plasma and serum. Figure $2 \mathrm{c}$ describes the MDACC patient sample and the CA9 values prior to and after nephrectomy. CA9 values decreased in $60 \%$ (21 out of 35) of MDACC patients postnephrectomy, while there was no change in $15 \%$ (five of 35 ) of patients and an increase in $25 \%$ (nine of 35). The correlation between preoperative CA9 values and tumor volume in this population was less than in the MGH population (Fig. 2d; $r=0.42$ ). To evaluate the impact of single points in the formation of this correlation, we removed patient MDACC 23, in which case the $r^{2}$ drops to 0.32 . On the other hand, by removing $\operatorname{MDACC} 7$, the single patient that despite the high tumor volume produces little CA9, the $r^{2}$ value improves to 0.52 . Our interpretation is that CA9 levels reflect to a certain degree of the tumor volume. Future studies with a larger patient population will be necessary to establish a precise correlation statistic to better characterize the relationship between CA9 blood levels and the presence of tumor.

Analyzed together, the data from both institutions indicate that in a subset of patients with localized clear cell RCC (57\%) undergoing curative nephrectomy, there is a decrease in the circulating levels of CA9 postoperatively. Comparison of preoperative to postoperative blood levels of CA9 in the combined MGH and MDACC patients demonstrates a significant decrease in CA9 levels ( $p$-value is 0.0097 , and the preoperative values are significantly higher than the postoperative values, with a $95 \%$ confidence interval of (6.7-81.8) and a median estimate of $32.3 \mathrm{pg} / \mathrm{mL}$, shown in Fig. 2e).

In contrast to patients with clear cell histology, patients undergoing nephrectomy for benign tumors or those of

\section{(A)}

\begin{tabular}{|c|c|c|c|}
\hline PT & Pre & Post & Histology \\
\hline 72 & 142.07 & 159.47 & $\begin{array}{l}\text { Oncocytoma/ } \\
\text { Chromophobe }\end{array}$ \\
\hline 119 & 123.46 & 131.69 & Chromophobe \\
\hline 126 & 100.53 & 190.04 & $\begin{array}{l}\text { TCC/ ureter and } \\
\text { kidney }\end{array}$ \\
\hline 185 & 140.88 & 476.68 & $\begin{array}{l}\text { Hamartoma, no } \\
\text { cancer }\end{array}$ \\
\hline 194 & 287.18 & 275.29 & Papillary \\
\hline 198 & 111.79 & 180.79 & Chromophobe \\
\hline
\end{tabular}

(B)

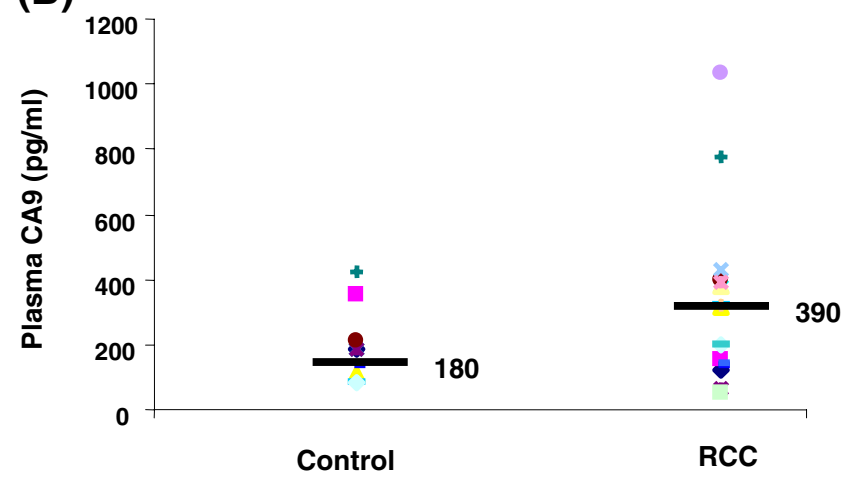

Fig. 3 Blood CA9 levels in nonclear cell kidney lesions and normal controls. a Changes in plasma levels of CA9 in patients undergoing nephrectomy for benign renal lesions or RCC of nonclear histology. Pre indicates blood CA9 levels prior to surgery and Post indicates the CA9 blood levels 4-5 weeks after nephrectomy. b Comparison of plasma levels of CA9 between RCC patients at presentation (RCC) and an independent set of normal control individuals (Control). Horizontal bars indicate median values (in $\mathrm{pg} / \mathrm{mL}$ ) 


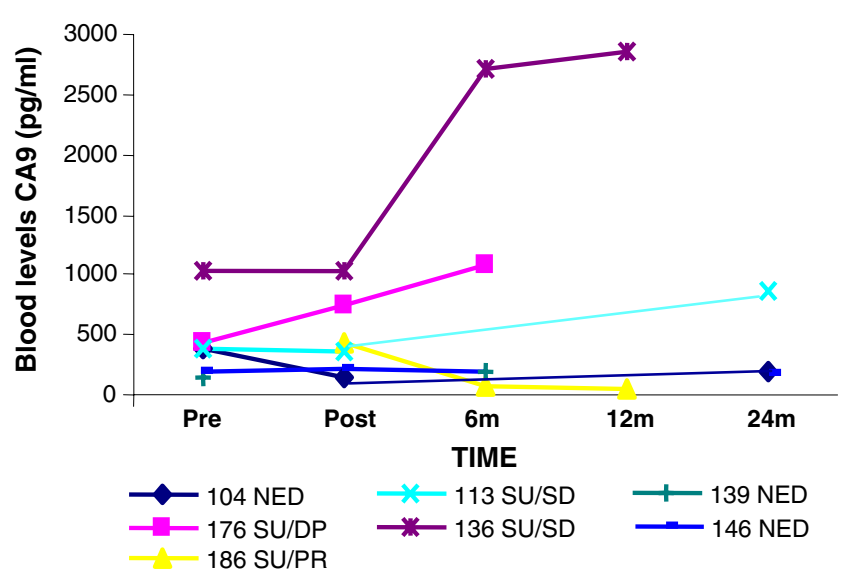

Fig. 4 Longitudinal measurements of plasma levels of CA9 in patients with clear cell RCC undergoing curative or debulking nephrectomy. $S U$ Treatment with suten, $G$ treatment with gemcitabine, $P R$ partial response, $S D$ stable disease, $D P$ disease progression, $N E D$ no evidence of disease. Specific values and times of blood collection are provided in Table 1

nonclear cell RCC histology did not have a significant decrease in plasma CA9 levels (Fig. 3a). Additionally, we measured CA9 in the plasma of patients without known $\mathrm{RCC}$, as a sample of "normal control" individuals; there is considerable overlap of CA9 plasma values in normal controls and RCC patients prior to nephrectomy (Fig. 3b).

To examine whether blood levels of CA9 correlate with disease activity over time and/or herald a local or systemic relapse of disease, we measured circulating CA9 levels in available plasma samples of clear cell RCC patients following curative or debulking nephrectomy (Fig. 4; Table 1). Patients 104, 139, and 146 remained disease-free at the indicated time of follow-up and their longitudinal CA9 plasma levels did not rise above post- or preoperative levels. Patients 176, 186, 113, and 136 presented with metastatic disease and underwent debulking nephrectomy. It is notable that in the three patients that can be evaluated, the postoperative levels of CA9 did not decline. Patient 186 responded to treatment and the clinical response correlated with a marked decline in CA9 plasma levels. Patients 176, 186,113 , and 136 had either stable disease under treatment with anti-angiogenic agents or disease progression. In the latter case, plasma levels of CA9 rose steadily.

\section{Discussion}

Our data demonstrate that circulating blood levels of CA9, a transcriptional target of HIF activity, declined in approximately $60 \%$ of clear cell RCC patients who underwent curative nephrectomy for organ-confined disease. RCC patients with nonclear cell histology or benign tumors had no change in CA9 plasma levels. Preoperative levels of CA9 correlated with tumor volume in patients with localized disease. None of the patients that presented with clinically overt metastatic disease and underwent debulking nephrectomy had a decrease in postoperative CA9 plasma levels. Moreover, follow-up measurements of CA9 plasma levels correlated with tumor progression or response to therapy in the small group of patients we examined.

CA9 levels decreased postoperatively in a defined subset of patients with localized disease. At this point, we do not know the common denominator that defines this patient subset. Several testable hypotheses that take into consideration our current knowledge of RCC biology could explain this heterogeneity. Loss-of-VHL function occurs in approximately $55-70 \%$ of patients with sporadic RCC, while the remaining cases harbor an undefined molecular defect. In

Table 1 Longitudinal measurements of plasma levels of CA9 in patients with clear cell RCC undergoing curative or debulking nephrectomy

\begin{tabular}{|c|c|c|c|c|c|c|c|c|}
\hline Patient & Sex & Pre & Post & 6 months & 12 months & 2 years & Stage & Follow-up \\
\hline 104 & M & $\begin{array}{l}381.26 \\
4 / 21 / 2005\end{array}$ & $\begin{array}{l}154.65 \\
6 / 23 / 2005\end{array}$ & & & $\begin{array}{l}201.2812444 \\
5 / 10 / 2007\end{array}$ & pT1b Nx Mx & NED 5/10/07 \\
\hline 176 & M & $\begin{array}{l}431.69 \\
12 / 13 / 06\end{array}$ & $\begin{array}{l}751.74 \\
2 / 15 / 07\end{array}$ & $\begin{array}{l}1,087.08 \\
\text { Post 5/10/07 }\end{array}$ & & & T1bN2M1 & Tx with SU/DP \\
\hline 186 & M & No pre & $\begin{array}{l}430.28 \\
2 / 27 / 07\end{array}$ & $\begin{array}{l}70.55 \\
\text { Post } 4 / 19 / 07\end{array}$ & $\begin{array}{l}52.43 \\
\text { Post 5/10/07 }\end{array}$ & & T3bN2M0, DN-1/07 & Tx with $\mathrm{SU}+\mathrm{G} / \mathrm{PR}$ \\
\hline 113 & M & $\begin{array}{l}394.42 \\
7 / 8 / 05\end{array}$ & $\begin{array}{l}359.81 \\
8 / 22 / 05\end{array}$ & & & $\begin{array}{l}860.55 \\
3 / 29 / 07\end{array}$ & $\mathrm{~T} 2 \mathrm{~N} 2 \mathrm{M} 1$ on presentation & Tx with SU/SD \\
\hline 136 & $\mathrm{~F}$ & $\begin{array}{l}1,032.19 \\
3 / 30 / 2006\end{array}$ & $\begin{array}{l}1,035.50 \\
5 / 11 / 2006\end{array}$ & $\begin{array}{l}2,711.44 \\
10 / 24 / 2006\end{array}$ & $\begin{array}{l}2,855.51 \\
2 / 27 / 2007\end{array}$ & & T3aN0M1 & $\mathrm{SU}(6 / 06) / \mathrm{SD}$ \\
\hline 139 & $\mathrm{~F}$ & $\begin{array}{l}143.28 \\
5 / 1 / 06\end{array}$ & & $\begin{array}{l}201.90 \\
12 / 19 / 2006\end{array}$ & & & T3aN0M0 & NED $(12 / 06)$ \\
\hline 146 & M & $\begin{array}{l}201.90 \\
6 / 8 / 2006\end{array}$ & $\begin{array}{l}208.27 \\
8 / 24 / 2006\end{array}$ & $\begin{array}{l}203.17 \\
1 / 16 / 2007\end{array}$ & & & T1bN0M0 & NED \\
\hline
\end{tabular}

$S U$ Treatment with sutent, $G$ treatment with gemcitabine, $P R$ partial response, $S D$ stable disease, $D P$ disease progression, $N E D$ no evidence of disease 
addition, patients with clear cell RCC may be divided in "high" and "low" expressers of CA9 by immunocytochemistry of the tumor. It is possible that circulating levels of CA9 is a sensitive marker of disease activity only for VHLassociated RCC patients or for the high CA9 expressers. It is also formally possible that clearance of CA9 from the circulation has different kinetic properties among individual patients, although a reasonable time interval (4 weeks at least) was allowed between pre- and postnephrectomy measurements. Lastly, it is interesting to note that CA12, another member of the CA family, is also overexpressed in clear cell RCC, albeit in a lower percentage of patients than CA9. It is possible that for a subset of patients CA12 is a more reliable marker for disease activity than CA9. We are currently developing an ELISA assay for CA12 to test this hypothesis. The observation that CA9 scores for only a subset of RCC patients emphasizes the need to discover and validate a panel of biomarkers for RCC activity. This heterogeneity may also explain the variability in the correlation between tumor volume and CA9 blood levels. This correlation may, to a certain degree, be attenuated by the presence of low expressing tumors, independent of size. However, the presence of a relative correlation in this small patient population demonstrates the link between circulating blood levels of CA9 and its source of origin.

All patients with disease progression had increased CA9 plasma levels, above that observed post- or preoperatively. One patient treated for systemic disease had a partial clinical response that correlated with reduced CA9 levels. It is therefore possible that, for a given population of RCC patients, fluctuation in CA9 levels over time may be a useful biomarker for early detection of tumor response or impeding disease relapse/progression. These data are clearly preliminary and large datasets are clearly required in order to incorporate changes in CA9 blood levels into clinical decision making. Our current data aim to highlight that CA9 should be considered and evaluated as a potential biomarker of RCC response to treatment. Alternatively, preoperative or postoperative levels of CA9 may have prognostic value and may be a useful independent factor for predicting disease free or overall survival.

Few biomarkers for RCC have been previously proposed in small patient samples. Of those, kidney injury molecule1 (KIM-1), a transmembrane glycoprotein upregulated in ischemic injury of the kidney epithelium, was reported to be elevated in RCC tumors and in the urine of RCC patients compared to normal controls [19]. No measurements of KIM-1 in the blood of RCC patients before or following nephrectomy have been reported so far. Elevated levels of nuclear matrix protein 22 (NMP22) has been detected in the urine of patients with RCC and a follow-up study indicated that specificity and sensitivity of RCC diagnosis ranged at $55 \%$ [20]. No data for blood levels of NMP22 have been reported. Matrix metalloproteinase activity has also been reported to be elevated in the urine of RCC patients [21]. Other reported biomarkers of RCC in the blood include a tumor-specific isoform of pyruvate kinase (TuPK; a HIF target) as well as plasma levels of IL-6, tumor necrosis factor $\alpha$, and circulating mRNA levels of prostate specific membrane antigen [22-25]. Few of these biomarkers have limited specificity and may reflect a systemic response to tumor burden. Others such as KIM-1, TuPK, and NMP22 could be incorporated into larger clinical studies evaluating the performance of a group of disease specific biomarkers [26].

In summary, we used gene expression comparison of signaling dependent human renal cell carcinoma cell lines to identify potential circulating biomarkers for clear cell RCC. We measured CA9 blood levels and demonstrated a correlation with the presence of disease in a subset of clear cell RCC patients. To the best of our knowledge, this is the first report of blood changes in a potential RCC biomarker postnephrectomy for localize RCC disease. Larger studies for definitive validation and clinical characterization of CA9 will be needed. The data presented herein supports this larger testing and underscores the need for discovery and validation of a panel of biomarkers that will globally reflect RCC disease activity.

Acknowledgements This work was funded in part by the DanaFarber/Harvard Cancer Center Kidney Cancer SPORE Grant (Project 1: Discovery of Biomarkers for Early Detection of RCC to OI).

\section{References}

1. Jemal A, Siegel R, Ward E, Murray T, Xu J, Thun MJ. Cancer statistics, 2007. CA Cancer J Clin 2007;57:43-66.

2. Iliopoulos O. Molecular biology of renal cell cancer and the identification of therapeutic targets. J Clin Oncol 2006;24:5593600.

3. Motzer RJ, Bander NH, Nanus DM. Renal cell carcinoma. N Engl J Med 1996;335:865-75.

4. Brugarolas J. Renal-cell carcinoma-molecular pathways and therapies. N Engl J Med 2007;356:185-7.

5. Escudier B, Eisen T, Stadler WM, et al. Sorafenib in advanced clear-cell renal-cell carcinoma. N Engl J Med 2007;356:125-34.

6. Kane RC, Farrell AT, Saber H, et al. Sorafenib for the treatment of advanced renal cell carcinoma. Clin Cancer Res 2006;12:7271-8.

7. Motzer R, Michaelson MD, Redman BG, et al. Activity of SU11248, a multitargeted inhibitor of vascular endothelial growth factor receptor and platelet-derived growth factor receptor, in patients with metastatic renal cell carcinoma. J Clin Oncol 2006;24:16-24.

8. Motzer RJ, Hutson TE, Tomczak P, et al. Sunitinib versus interferon alfa in metastatic renal-cell carcinoma. N Engl J Med 2007;356:115-24.

9. Hudes G, Carducci M, Tomczak P, et al. Temsirolimus, interferon alfa, or both for advanced renal-cell carcinoma. N Engl J Med 2007;356:2271-81. 
10. Liao SY, Aurelio ON, Jan K, Zavada J, Stanbridge EJ. Identification of the MN/CA9 protein as a reliable diagnostic biomarker of clear cell carcinoma of the kidney. Cancer Res 1997;57:2827-31.

11. Wykoff CC, Beasley NJ, Watson PH, et al. Hypoxia-inducible expression of tumor-associated carbonic anhydrases. Cancer Res 2000;60:7075-83.

12. Bui MH, Visapaa H, Seligson D, et al. Prognostic value of carbonic anhydrase IX and KI67 as predictors of survival for renal clear cell carcinoma. J Urol 2004;171:2461-6.

13. Atkins M, Regan M, McDermott D, et al. Carbonic anhydrase IX expression predicts outcome of interleukin 2 therapy for renal cancer. Clin Cancer Res 2005;11:3714-21.

14. Li G, Feng G, Gentil-Perret A, Genin C, Tostain J. CA9 gene expression in conventional renal cell carcinoma: a potential marker for prediction of early metastasis after nephrectomy. Clin Exp Metastasis 2007;24(3):149-55.

15. Jones J, Otu H, Spentzos D, et al. Gene signatures of progression and metastasis in renal cell cancer. Clin Cancer Res 2005;11:5730-9.

16. Iliopoulos O, Kibel A, Gray S, Kaelin WG. Tumor suppression by the human von Hippel-Lindau gene product. Nat Med 1995;1:822-6.

17. Zimmer M, Doucette D, Siddiqui N, Iliopoulos O. Inhibition of hypoxia inducible factor is sufficient for growth suppression of VHL-/- tumors. Mol Cancer Res 2004;2:89-95.

18. Kondo K, Kim WY, Lechpammer M, Kaelin WG. Inhibition of HIF2alpha is sufficient to suppress pVHL-defective tumor growth. PLoS Biol 2003;1:83.
19. Han WK, Bailly V, Abichandani R, Thadhani R, Bonventre JV. Kidney injury molecule-1 (KIM-1): a novel biomarker for human renal proximal tubule injury. Kidney Int 2002;62:237-44.

20. Emmert-Buck MR, Gillespie JW, Paweletz CP, et al. An approach to proteomic analysis of human tumors. Mol Carcinog 2000;27: $158-65$.

21. Sherief MH, Low SH, Miura M, Kudo N, Novick AC, Weimbs T. Matrix metalloproteinase activity in urine of patients with renal cell carcinoma leads to degradation of extracellular matrix proteins: possible use as a screening assay. J Urol 2003;169: $1530-4$.

22. Wechsel HW, Petri E, Bichler KH, Feil G. Marker for renal cell carcinoma (RCC): the dimeric form of pyruvate kinase type M2 (Tu M2-PK). Anticancer Res 1999;19:2583-90.

23. Yoshida N, Ikemoto S, Narita $\mathrm{K}$, et al. Interleukin-6, tumour necrosis factor alpha and interleukin-1beta in patients with renal cell carcinoma. Br J Cancer 2002;86:1396-400.

24. Mulders P, Bleumer I, Oosterwijk E. Tumor antigens and markers in renal cell carcinoma. Urol Clin North Am 2003;30: 455-65.

25. de la Taille A, Cao Y, Sawczuk IS, et al. Detection of prostatespecific membrane antigen expressing cells in blood obtained from renal cancer patients: a potential biomarker of vascular invasion. Cancer Detect Prev 2000;24:579-88.

26. Oremek GM, Sapoutzis N, Kramer W, Bickeboller R, Jonas D. Value of tumor M2 (Tu M2-PK) in patients with renal carcinoma. Anticancer Res 2000;20:5095-8. 